triennial screening guidelines. All women undertook self-collection and the majority of women reported high perceived acceptability, safety, and accuracy of HPV self-collection. HPV $16 / 18$ positivity was $7.6 \%$, with $40 \%$ co-infected with HIV. Overall HIV prevalence was $16.4 \%$, however, over $25 \%$ of women had unknown HIV status based on medical chart review.

Conclusion HPV self-collection was highly acceptable as part of community-based integrative reproductive health services. Despite being a traditionally underserved population, and women self-reporting being overdue for screening, over half the women were up to date on cervix screening, albeit regular screening was lacking for many. The findings from this feasibility study will inform future implementation of HPV self-collection to improve and maintain regular cervix screening services in street entrenched women.

Disclosure No significant relationships.

\section{P698 COMPREHENSIVE HEALTHCARE INTERVENTION FOR FEMALE SEX WORKERS IN ETHIOPIAN STI CLINICS: EXPERIENCE FROM MEKELLE UNIVERSITY}

\begin{abstract}
${ }^{1}$ Tesfay Gebrehiwot*, ${ }^{2}$ Zerihun Abebe, ${ }^{3}$ Dejen Yemane, ${ }^{3}$ Solomon Gebremariam, ${ }^{4}$ Loko Bongassie. 'Mekelle University, School of Public Health, Department of Health Systems, Mekelle, Ethiopia; ${ }^{2}$ Saint Paulos Millenium Medical College, Addis Ababa, Ethiopia; ${ }^{3}$ Mekelle University, Mekelle, Ethiopia; ${ }^{4}$ Ethiopian Pharmacuetical Fund Supply Agency, Mekelle, Ethiopia
\end{abstract}

\subsection{6/sextrans-2019-sti.764}

Background Evidence suggests that the presence of untreated sexually transmitted infections (STIs) increases the chance of HIV transmission during unprotected sex. In the Ethiopian context, many female sex workers live in poor conditions in rented slums and are not typically known or recognised by local authorities, making them unable to access health facilities. Methods Data were obtained from a register of female sex workers recorded for purpose of service provision at confidential STI clinics in Mekelle and Adigrat, Ethiopia, from May 2010 to August 2015 and from May 2011 to August 2015, respectively. A simple descriptive analysis of services delivered to patients was performed.

Results Among the 6288 patients included in this study, the prevalence of STIs was 23.4\%. Of these, $12.9 \%(814 / 6288)$ of patients presented with vaginal discharge, $7.9 \%(490 / 6288)$ with genital ulcers and $2.3 \%(158 / 6288)$ with lower abdominal pain (as per the WHO syndromic approach to STIs). Moreover, 180 cases of genital ulcer were tested for syphilis with the VDRL test; 36 (20\%) tested positive for active infection. The HIV prevalence declined from $10 \%$ in 2010 to $1.1 \%$ in 2015 . The frequency of STIs amongst repeat patients was considerably lower than that in new presentations.

Conclusions HIV prevalence declined from 10\% in 2010 to $1.1 \%$ in 2015 . Compared to new cases, the frequency of STIs among repeat clients was extremely low, suggesting that the cumulative effect of peer promotion and preventative sexual health education is effective in reducing the rates of STIs among vulnerable populations. Clinic and workplace geography, hours of clinic operation, confidentiality and peer outreach are important factors in the prevention and control of STI/HIV infection in key sex worker populations. A comprehensive clinic intervention enhances early diagnosis and treatment of STIs and increases the proportion of sex workers accessing HIV treatment services.
Disclosure No significant relationships.

\section{P699 ROLE OF MANAGEMENT IN ENHANCING EFFICIENCY OF FEMALE SEX WORKERS HIV PROGRAMS IN NIGERIA}

Idoteyin Ezirim*, Francis Agbo. National Agency for the Control of AIDS, Research, Monitoring and Evaluation, Abuja, Nigeria

\subsection{6/sextrans-2019-sti.765}

Background HIV is high among female sex workers (FSW). Community-based organizations (CBOs) staff and volunteers, deliver HIV services to FSWs. One overlooked avenue for enhancing efficiency in delivery of services is good personnel management. This study was done to understand challenges faced by $\mathrm{CBO}$ staff during service delivery and management practices hindering their output.

Methods Qualitative methods were used in this study. Staffs and volunteers from 9 CBOs in three states, Abuja, Lagos and Nasarrawa participated in the study. States were selected using convenience sampling. Journals were distributed to $\mathrm{CBO}$ staff to document their daily challenges for 3-6 weeks. After 6 weeks, we collected 23 journals, read entries and conducted 6 non-participant observations and 31 key informant interviews. Information from the completed journals, interviews and observations, were grouped into themes to reveal insights. Using these insights, we conducted brainstorming sessions with CBOs to generate problem-solving ideas. The most relevant ideas were tested in focus groups.

Results The study revealed that CBOs provide HIV services as agreed with donors. They did not solicit and implement feedback from volunteers. Instituting feedback mechanisms will make CBO personnel feel relevant and serve as an avenue for harvesting solutions to challenges in service delivery. The study showed that FSW peer session schedules change constantly and volunteers find it difficult to communicate changes to CBO staff resulting in poor supervision. Poor supervision affects the quality of services volunteers provide. Therefore ensuring communication within $\mathrm{CBO}$ personnel, will improve coordination of activities and quality of HIV services delivered. Finally, while CBOs have systems in place to reward performance, these systems were underutilized and not incentivized. If reward systems for best practices are rejuvenated, it will motivate personnel.

Conclusion Good personnel management can enhance FSW HIV programs. Feedback mechanisms, communication and reward systems are tools that will ensure efficient delivery HIV prevention services.

Disclosure No significant relationships.

\section{P700 UNINTENDED PREGNANCY AMONG FEMALE SEX WORKERS IN MEKELLE CITY, NORTHERN ETHIOPIA: A CROSS-SECTIONAL STUDY}

${ }^{1}$ Tesfay Gebrehiwot*, ${ }^{2}$ Rishan Weldegebriel, ${ }^{3}$ Mussie Alemayehu. 'Mekelle University, School of Public Health, Department of Health Systems, Mekelle, Ethiopia; ${ }^{2}$ Mekelle University, City, Ethiopia; ${ }^{3}$ Mekelle University, Mekelle, Ethiopia

\subsection{6/sextrans-2019-sti.766}

Background Unintended pregnancy is a significant public health concern in the world. Particularly, female sex workers are exposed to the risk of unintended pregnancy, abortion and 
their consequences. This study assessed unintended pregnancy and its associated factors among female sex workers in Northern Ethiopia.

Methods A community based cross-sectional study was conducted among 346 female sex workers at five localities of Mekelle city from March to April, 2014. Sex workers were selected with simple random sampling technique using sampling frame obtained from urban health extension program. Epi-data version 3.1 was used to enter data and analysis was done using SPSS version 20. Bivariate and multivariate logistic regressions were performed to identify factors associated with unintended pregnancy using odds ratio and 95\% confidence interval with P-value of 0.05 .

Results The magnitude of unintended pregnancy among female sex workers was $28.6 \%$. During this period, 59 women had abortion which represents three-fifths, (59.6\%) of those with unintended pregnancy. Female sex workers who had history of abortion formerly had 15.6 (AOR $=15.64$ 95\% CI: [8.03, 30.47]) times higher odds of unintended pregnancy compared to their counterparts. Sex workers who had steady partners had $2.9(\mathrm{AOR}=2.87,95 \% \mathrm{CI}:[1.47,5.61])$ times higher odds of have unintended pregnancy than those who hadn't. Drug users had 2.7 (AOR $=2.68,95 \% \mathrm{CI}$ : [1.30, 5.52]) times higher odds of unintended pregnancy than those who hadn't use. Sex workers who had longer duration in sex work were $67 \%$ less likely to have unintended pregnancy than those with $<12$ months (AOR $=0.33$, 95\% CI: [0.11, 0.95]).

Conclusion High level of unintended pregnancy and a range of associated factors were identified among sex workers. Improving utilization of effective pregnancy prevention methods in a consistent manner can avert the existing high level of unintended pregnancy among female sex workers.

Disclosure No significant relationships.

\section{P701 TIME TRENDS IN PREVALENCE AND INCIDENCE OF HIV, GONORRHEA AND CHLAMYDIA AMONG FEMALE SEX WORKERS IN BENIN, 2008-2018}

${ }^{1}$ Michel Alary*, ${ }^{2}$ Luc Béhanzin, ${ }^{2}$ Fernand Guédou, ${ }^{2}$ Ella Goma-Matsétsé, ${ }^{2}$ Marlène AzaGnandji, ${ }^{3}$ Djimon Marcel Zannou, 'Souleymane Diabaté, ${ }^{3}$ Dissou Affolabi, ${ }^{4}$ René Kêkê, ${ }^{4}$ Moussa Bachabi, ${ }^{3}$ Flore Gangbo. ${ }^{1} \mathrm{CHU}$ de Quebec - Université Laval, Quebec, Canada; ${ }^{2}$ Dispensaire IST, Cotonou, Benin; 'Université d'Abomey-Calavi, Cotonou, Benin; ${ }^{4}$ Programme Santé de lutte contre le SIDA, Cotonou, Benin

\subsection{6/sextrans-2019-sti.767}

Background The conduction of 3 cohort studies among professional female sex workers (FSWs), e.g. women whose main source of revenue is sex work, since 2008 in Benin allowed the estimation of time trends in HIV, gonorrhea and chlamydia prevalence and incidence in this key population over the last decade.

Methods The 3 cohort studies were conducted from 09/200803/2012, 10/2014-12/2016 and 04/2017-09/2018, respectively. Women were recruited at the Dispensaire IST, a FSW-dedicated clinic, after providing informed consent. Follow-up was quarterly in the first 2 studies and bi-annual in the latest one. FSWs were tested for HIV (rapid test with confirmatory assay according to Benin guidelines), gonorrhea and chlamydia (BD ProbeTec $^{\mathrm{TM}} \mathrm{CT} / \mathrm{NG}$, Becton Dickinson Inc.) at baseline and at each follow-up for HIV and semi-annually for gonorrhea and chlamydia. Questionnaires were administered.
Results In all studies, median age was 32-33 years and the proportion of women not born in Benin 50-60\%. HIV [gonorrhea (chlamydia)] prevalence was $37.1 \%$ [4.3\% (3.5\%)] in $2008(\mathrm{n}=396), 29.1 \%$ [9.7\% (4.8\%)] in $2014(\mathrm{n}=361)$ and $26.0 \%$ [13.8\% (7.4\%)] in $2017(\mathrm{n}=312)$. There was a significant downward (upward) trend in HIV (gonorrhea and chlamydia) prevalence: $\mathrm{p}<0.001 \quad(\mathrm{p}<0.001$ and $\mathrm{p}=0.03)$. Among respectively 319, 299 and 213 women with follow-up, gonorrhea (chlamydia) incidence was 8.9 (2.1), 9.0 (4.6) and 14.8 (5.8) per 100 person-years; $p=0.07(p=0.003)$. HIV incidence was $1.4,0.8$ and 0.7 per 100 person-years in 2008-12, 2014-16 and 2017-18, respectively $(\mathrm{p}=0.41)$.

Conclusion HIV prevalence is decreasing, but still high, whereas HIV incidence is low in this highly mobile key population. This combination of high prevalence and low incidence is likely due to HIV treatment scale-up over the last decade, including the adoption of an HIV "test and treat" strategy since 2016 in Benin. However, the increase in both gonorrhea and chlamydia is worrying and calls for renewed control strategies for these curable infections.

Disclosure No significant relationships.

\section{P702 CHARACTERIZING HIV-ASSOCIATED VULNERABILITIES AMONG WOMEN ENGAGED IN TRANSACTIONAL SEX TO DESIGN PROGRAMS IN UKRAINE}

${ }^{1}$ Daryna Pavlova*, ${ }^{2}$ Olga Balakireva, ${ }^{3}$ Eve Cheuk, ${ }^{4}$ Shajy Isac, ${ }^{3}$ Robert Lorway, ${ }^{3}$ Michael Pickles, ${ }^{5}$ Paul Sandstrom, ${ }^{6}$ Sharmistha Mishra, ${ }^{3}$ James Blanchard, ${ }^{3}$ Marissa Becker. "NGO "Ukrainian Institute for Social Research after Oleksandr Yaremenko", Kyiv, Ukraine; ${ }^{2}$ Institute for Economics and Forecasting, Ukrainian National Academy of Sciences, Kyiv, Ukraine; ${ }^{3}$ Center for Global Public Health, Department of Community Health Sciences, University of Manitoba, Winnipeg, Canada; ${ }^{4}$ India Health Action Trust, Bangalore, India; ${ }^{5}$ National HIV and Retrovirology Laboratory, JC Wilt Infectious Diseases Research Centre, Winnipeg, Canada; ' ${ }^{6} i$ Ka Shing Knowledge Institute, St. Michael's Hospital, University of Toronto, Toronto, Canada

\subsection{6/sextrans-2019-sti.768}

Background Evidence suggests a range of HIV-associated vulnerabilities associated with the exchange of sex for money or other material goods, but most research and programs in Ukraine focus on formal sex work. We sought to describe the prevalence of HIV and HIV-associated vulnerabilities among adolescent girls and young women engaged in transactional sex outside of formal sex work.

Methods We conducted a cross-sectional bio-behavioral study in Dnipro, Ukraine in 2016 of young women (14-24 years). 469 participants were recruited who reported transactional sex but not sex work, from places where female sex workers solicit clients. Transaction sex was defined as a sexual engagement with the expectation of receiving, gifts or other resources in return, when the price of sex is often not negotiated upfront and is implicitly understood.

Results Mean age of participants was 21.2 years. The mean age among participants at first sex was 16.0 years (range 1221). At first sex $34 \%$ (160) received gifts or money, and $7 \%$ (34) reported forced first sex. During the past week, $81 \%$ (378) had sex with a regular transactional partner, with whom $35 \%$ (132) had condomless sex. In the past month, 29\% (137) had sex while inebriated with regular transactional partners, and 64\% (299) did not use/remember whether a 